\title{
Design, Synthesis, and Implementation of Sodium Silylsilanolates as Silyl Transfer Reagent
}

\author{
Hiroki Yamagishi, Hayate Saito, Jun Shimokawa, ${ }^{*}$ Hideki Yorimitsu* \\ Department of Chemistry, Graduate School of Science, Kyoto University, Kyoto, 606-8502, Japan.
}

\begin{abstract}
There is an increasing demand for facile delivery of silyl groups onto organic bioactive molecules. One of the common methods of silylation via a transition metal-catalyzed coupling reaction employs hydrosilane, disilane, and silylborane as major silicon sources. However, labile nature of the reagents or harsh reaction conditions sometimes renders them inadequate for the purpose. Thus, a more versatile alternative source of silyl groups has been desired. We hereby report a design, synthesis, and implementation of new storable sodium silylsilanolates that can be used for the silylation of aryl halides and pseudohalides in the presence of a palladium catalyst. The new method allows a latestage functionalization of polyfunctionalized compounds with a variety of silyl groups, such as trimethylsilyl (TMS) group. Mechanistic studies indicate that 1) a nucleophilic silanolate attacks a palladium center to afford a silylsilanolate-coordinated arylpalladium intermediate and 2) a polymeric cluster of silanolate species assists in the intramolecular migration of silyl groups, which would promote an efficient transmetalation.
\end{abstract}

Silicon typically adopts four covalent, tetrahedrally disposed bonds in molecular architectures, so that it resembles one of the most fundamental elements of Life, carbon. The major difference between these two group 14 elements lies in electronegativity and in the bond length to the adjacent atoms. Thus, in the realm of silicon-containing drugs and bioactive molecules, ${ }^{1}$ a carbon atom could be exchanged to a silicon atom as a bioisostere to modify the physical and biological characters. Through these strategies known as "silicon switch" ${ }^{1 a "}$, silicon-containing bioactive molecules have been successfully devised (Figure 1). RXR-selective retinoid antagonist, bexarotene, has been redesigned to disila-bexarotene by exchanging two carbon atoms with silicon atoms without detrimental effect on bioactivity. ${ }^{2}$ The silicon switch strategy has also effectively proposed potent sila-analogues of acaricide Cyflumetofen ${ }^{3}$ and p38 MAP kinase inhibitor Doramapimod ${ }^{4}$ (BIRB 796). As illustrated in these examples, the substitution of tert-butyl group with a bioisosteric trimethylsilyl (TMS) group is an intriguing tactic for changing physico-chemical properties such as human microsomal stability, without lowering the biological activities.

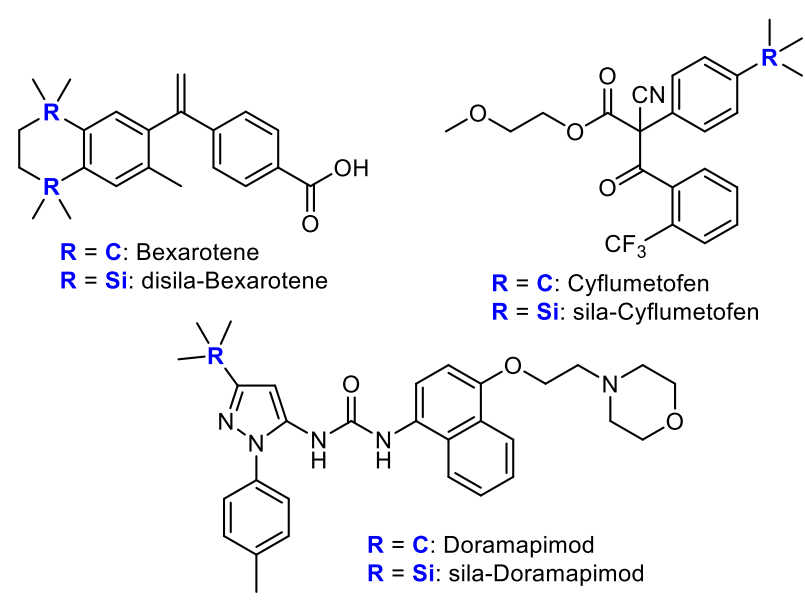

Figure 1. Sila-analogs Developed via Carbon/Silicon Switch Strategy.
A. Silylating Reagents Employed in Transition Metal-catalyzed Silylation of Aryl (pseudo)Halides

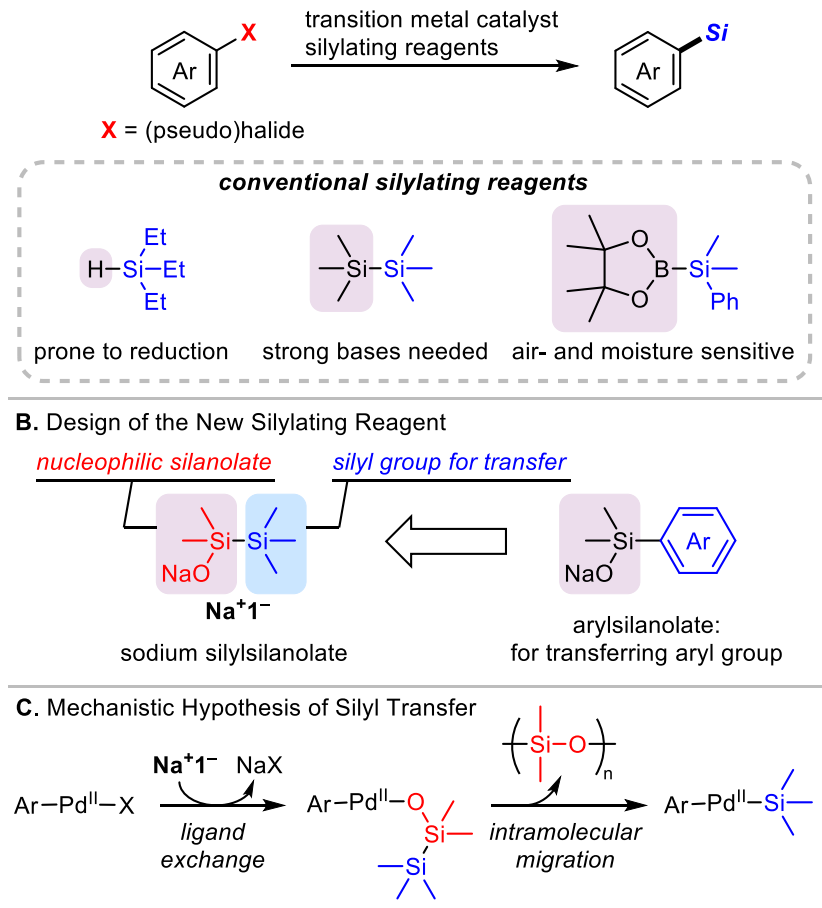

Figure 2. Blueprint for Development of Sodium Silylsilanolate. 
Despite these successful implementation of the silicon switch strategy, synthetic approaches to complex siliconcontaining molecules have been restricted. We hypothesized that this difficulty would be due to the lack of an appropriate reagent for transition metal-catalyzed silylation of aryl halides, which could also be amenable to the latestage transformation of functionalized molecules (Figure 2A). Commonly used reagents for those silylation can be mainly classified into three silicon species, hydrosilanes, disilanes, and silylboranes. Hydrosilanes often provide reduced products during transition metal-catalyzed silylation reaction, which often complicates the reaction consequences. ${ }^{5}$ Particularly, trimethylhydrosilane is a gaseous and pyrophoric reagent that is practically unrealistic to use in the laboratory. Symmetric disilanes, such as hexamethyldisilane, are less likely to cause transmetalation, so that relatively high temperature $\left(>100^{\circ} \mathrm{C}\right)$ and strong bases are often necessary for the activation. ${ }^{6}$ Thus, the use of disilanes leads to the reduced functional group tolerance. Silylboranes ${ }^{7}$ are relatively new breed of silylation reagents that can be used in transition metal-catalyzed silylation of aryl (pseudo)halides. ${ }^{7 b, 8}$ While silylboranes bearing a bulky silyl groups are reported to be stable, ${ }^{9}$ typical silylborane $\mathrm{Me}_{2} \mathrm{PhSi}-\mathrm{Bpin}$ is known to be air- and moisture-sensitive ${ }^{7 b}$ and $\mathrm{Me}_{3} \mathrm{Si}-\mathrm{Bp}$ in is inevitably fairly labile so that it is reported to hydrolyze during purification. ${ }^{10}$ This labile nature renders silylboranes inappropriate to deliver TMS group. In terms of silylation reaction, the simplest trialkylsilyl group, TMS, is definitely no trivial one. By going through these three reagents, it is now evident that the development of a novel practical silylating reagent is necessary for more efficient silylation under mild conditions.

Herein, we propose sodium trimethylsilyldimethylsilanolate $\left(\mathrm{Na}^{+} \mathbf{1}^{-}\right)$as a new silylating reagent that works in the presence of palladium catalyst (Figure 2B). The design of this reagent was inspired by analogy to arylsilanolates that have been known as reagents for transferring aryl groups in palladium-catalyzed cross-coupling reactions. ${ }^{11}$ The molecular structure of $\mathbf{N a}^{+} \mathbf{1}^{-}$contains one $\mathrm{Si}-\mathrm{Si}$ bond that connects a TMS group to be delivered and a nucleophilic silanolate as a catapult. We hypothesized the mode of migration of a silyl group from silylsilanolate shown in Figure $2 \mathrm{C}$, based upon a similar system for arylsilanolate proposed by Denmark. ${ }^{119}$ In contrast to the ordinary disilanes, anionic silylsilanolate can act as a nucleophile that attacks the palladium (II) center to form a silylsilanolate-coordinated intermediate. This proximity effect would facilitate an intramolecular delivery of the terminal silyl group to the palladium center, with concomitant formation of a waste polysiloxane.

$\mathrm{Na}^{+} \mathbf{1}^{-}$was easily synthesized from commercially available chloropentamethyldisilane $\mathbf{1}$ over two steps (Scheme 1A): hydrolysis of a chlorosilane in an acetate buffer to afford a silanol and the subsequent deprotonation with $\mathrm{NaH}$. The reagent was obtained as an analytically pure, mildly hygroscopic, and thermally stable white powder that can be easily handled in a dry atmosphere. Sodium silylsilanolates other than $\mathbf{~ N a}^{+} \mathbf{1}^{-}$were synthesized as shown in Scheme $1 \mathrm{~B}$. Commercially available 1,2-dichlorotetramethyldisilane was treated with nucleophilic organometallic species $(\mathrm{BnMgBr}, t \mathrm{BuLi}$, allyl $\mathrm{ZnCl})$ to mediate mono-substitutions to give the corresponding chlorodisilanes $\mathbf{2}$, 3, and $\mathbf{4}^{12}$. Hydrolysis of 2-4 followed by deprotonation with $\mathrm{NaH}$ provided the corresponding sodium silylsilanolates $\mathbf{N a}^{+} \mathbf{2}^{-}-$ $\mathrm{Na}^{+} 4^{-}$in good yields. $\mathrm{Na}^{+} \mathbf{2}^{-}$and $\mathrm{Na}^{+} 3^{-}$were obtained as white solids, and $\mathrm{Na}^{+} \mathbf{4}^{-}$was isolated as a sticky oil.

In order to evaluate the synthetic utility of sodium silylsilanolate, we studied the silylation of aryl bromide $\mathbf{5}$ in the presence of a palladium catalyst with $\mathbf{N a}^{+} \mathbf{1}^{-}$(Table 1). Under our optimized standard conditions, treatment of ethyl 4bromobenzoate (5) with preformed MePhos Pd G4 (3 mol\%), ${ }^{13} \mathbf{~ N a}^{+} \mathbf{1}^{-}$(2.0 equiv) in 1,2-dichloroethane (DCE) as the solvent at $50^{\circ} \mathrm{C}$ for $2 \mathrm{~h}$ provided the silylated product 6 in $89 \%$ NMR yield ( $88 \%$ isolated yield) (Entry 1). The yield of 6 was competitive (83\%) with the use of the catalyst generated in situ from $\mathrm{Pd}_{2} \mathrm{dba}_{3}$ and MePhos (Entry 2). An influence of ligands on the efficiency of the reaction was examined first. Monodentate ligands, $\mathrm{PC} \mathrm{y}_{3}, \mathrm{CyJ}_{\mathrm{J}} \mathrm{h} n \mathrm{Phos}$, and JohnPhos afforded 6 in competitive yet lower yields (51-81\%) (Entry 3-5). An acceptable result was also obtained with $\mathrm{N}$ heterocyclic carbene complex (IPr)Pd(allyl) Cl as a catalyst (73\%) (Entry 6). A bidentate phosphine ligand, dppe, was ineffective (7\%) in the current reaction system (Entry 7). Use of potassium silylsilanolate, $\mathbf{K}^{\mathbf{+}} \mathbf{1}^{-}$, showed lower efficiency (Entry 8), which underscored the importance of the choice of the countercation for efficient silylation. The reaction in toluene was similarly efficient (74\%), while low yields were observed in THF and $\mathrm{CH}_{3} \mathrm{CN}$ with the recovery of most of the substrate (Entry 9-11) in concomitant with the formation of the reduced product ( $<20 \%)$. No conversion of 5 was observed in the absence of a palladium catalyst (Entry 12). 
Scheme 1. Synthesis of Sodium Silylsilanolates.

A. Synthesis of Sodium Trimethysilyldimethylsilanolate

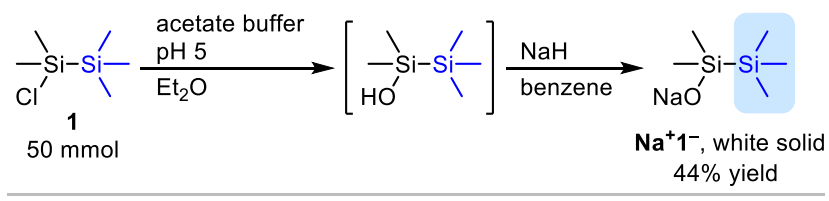

B. Synthesis of Sodium Dimethylalkylsilylsilanolate via Mono-substitution of 1,2-Dichlorotetramethyldisilane
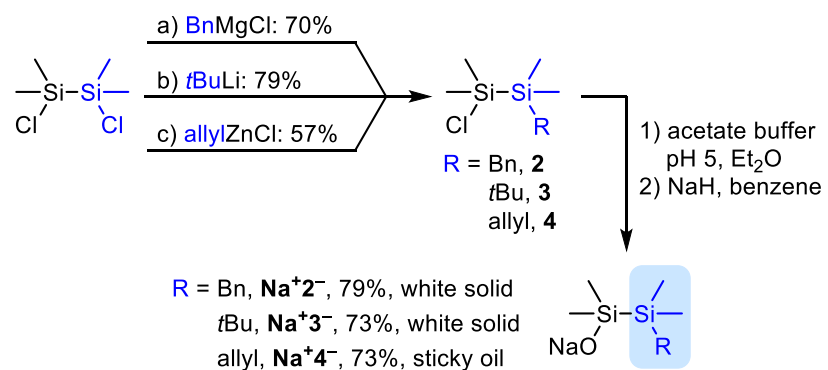

a) 1.05 equiv 1,2-dichlorotetramethyldisilane, 1.0 equiv $\mathrm{BnMgCl}, \mathrm{THF}, 0$ to $50^{\circ} \mathrm{C}, 4 \mathrm{~h}$. b) 1.03 equiv 1,2-dichlorotetramethyldisilane, 1.0 equiv $t B u L i$, hexane, reflux, 13 h. c) 1.0 equiv 1,2-dichlorotetramethyldisilane, 1.0 equiv allylZnCl, $\mathrm{THF}, 0^{\circ} \mathrm{C}$ to r.t., $4 \mathrm{~h}$.

Table 1. Optimization of the Reaction Conditions.

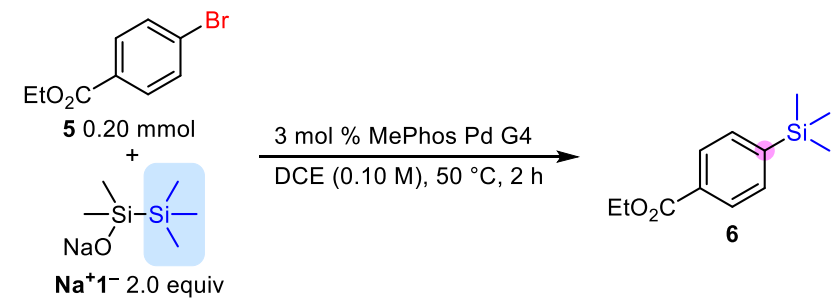

\begin{tabular}{|c|c|c|}
\hline Entry & Deviations from standard conditions & Yield (\%) ${ }^{\mathrm{a}}$ \\
\hline 1 & none & $89(88)^{b}$ \\
\hline 2 & $1.5 \mathrm{~mol} \% \mathrm{Pd}_{2} \mathrm{dba}_{3}+3 \mathrm{~mol} \%$ MePhos & 83 \\
\hline 3 & $1.5 \mathrm{~mol}_{0} \mathrm{Pd}_{2} \mathrm{dba}_{3}+3 \mathrm{~mol} \% \mathrm{PCy}_{3}$ & 80 \\
\hline 4 & $1.5 \mathrm{~mol} \% \mathrm{Pd}_{2} \mathrm{dba}_{3}+3 \mathrm{~mol} \%$ CyJohnPhos & 75 \\
\hline 5 & $1.5 \mathrm{~mol} \% \mathrm{Pd}_{2} \mathrm{dba}_{3}+3 \mathrm{~mol} \%$ JohnPhos & 51 \\
\hline 6 & $3 \mathrm{~mol} \%$ (IPr)Pd(allyl)Cl & 72 \\
\hline 7 & $1.5 \mathrm{~mol} \% \mathrm{Pd}_{2} \mathrm{dba}_{3}+3 \mathrm{~mol} \% \mathrm{dppe}$ & 7 \\
\hline 8 & $\mathrm{~K}^{+} \mathbf{1}^{-}$ & 31 \\
\hline 9 & toluene & 74 \\
\hline 10 & THF & 25 \\
\hline 11 & $\mathrm{CH}_{3} \mathrm{CN}$ & 14 \\
\hline 12 & without MePhos Pd G4 & 0 \\
\hline
\end{tabular}

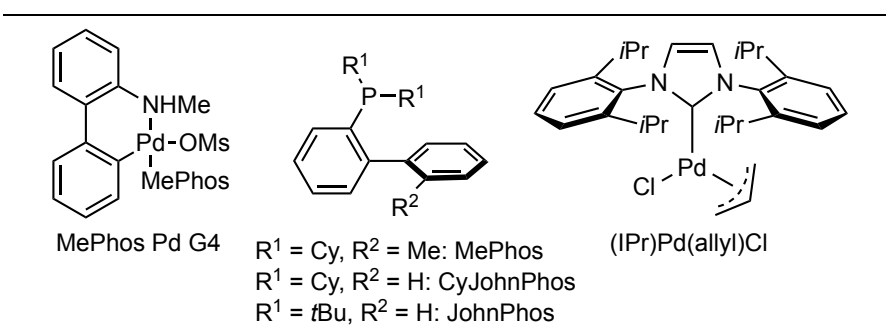

aYields were determined by ${ }^{1} \mathrm{H}$ NMR using 1,3,5-trimethoxybenzene as an internal standard. ${ }^{b}$ Isolated yield ( $0.50 \mathrm{mmol}$ scale). 
Table 2. Scope of Silylation of Aryl Bromides.

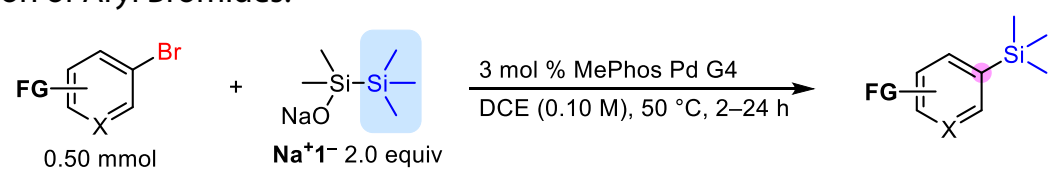<smiles>CCOC(=O)c1ccc([Si](C)(C)C)cc1</smiles><smiles>C=Cc1ccc([Si](C)(C)C)cc1</smiles>

$13,92 \%$<smiles>COc1ccc([Si](C)(C)C)cc1</smiles>

$14,81 \%$<smiles>COc1cccc([Si](C)(C)C)c1</smiles>

$15,81 \%$<smiles>COc1ccccc1[Si](C)(C)C</smiles>

16, $73 \%$<smiles>C[AsH3]Oc1ccc([Si](C)(C)C)cc1</smiles>

$17,73 \%$<smiles>C[Si](C)(C)c1ccc(N=[N+]([O-])c2ccccc2)cc1</smiles>

$18,73 \%$<smiles>C[Si](C)(C)c1ccc(N=[W])cc1</smiles>

$19,69 \%$

\section{B. Heterocycles}<smiles>C[Si](C)(C)c1ccc2occc2c1</smiles>

$20,98 \%$<smiles>C[Si](C)(C)c1ccc2sccc2c1</smiles>

21, $93 \%$<smiles>Cn1ccc2cc([Si](C)(C)C)ccc21</smiles>

22, $97 \%$<smiles>Cn1ccc2cc(S(C)(C)C)ccc21</smiles>

23, $100 \%$<smiles>Cc1nn(N)c(C)c1[Si](C)(C)C</smiles>

24, $53 \%$<smiles>C[Si](C)(C)c1cnc2ccccc2c1</smiles>

$25,85 \%$<smiles>C[Si](C)(C)c1ccc(N2CCOCC2)nc1</smiles>

26, $91 \%$<smiles>C[Si](C)(C)c1cnc(OC(=O)c2ccccc2)nc1</smiles>

27, $80 \%$<smiles>C[Si](C)(C)c1cnc(N2CCN(C(=O)c3ccccc3)CC2)nc1</smiles>

28, $92 \%$

(with $\left.\mathrm{Si}_{2} \mathrm{Me}_{6}: 31 \%\right)^{\mathrm{c}}$

C. Bioactive Molecules Containing TMS Group

D. Drug-like Complex Molecules

Sulfadimethoxine analog<smiles>COc1cc(N(C)S(=O)(=O)c2ccc([Si](C)(C)C)cc2)nc(OC)n1</smiles><smiles>COC(=O)c1cccc(-c2noc(-c3ccc([Si](C)(C)C)cc3F)n2)c1</smiles><smiles>C[Si](C)(C)c1ccc(-c2cc(C(F)(F)F)nn2-c2ccc(S(N)(=O)=O)cc2)cc1</smiles>

from SC-558

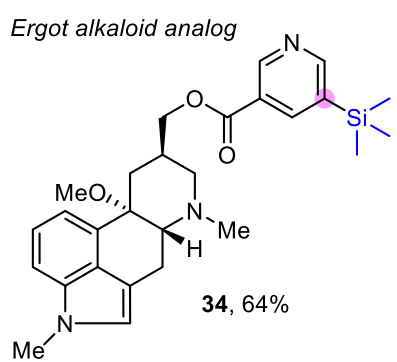

from Nicergoline<smiles>C[Si](C)(C)c1cccc(C(=O)[Na])c1</smiles>

Zifrosilone (29) $72 \%$

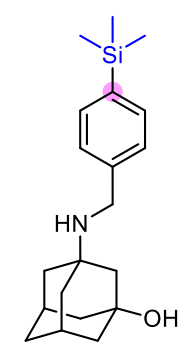

AM2-S31N inhibitor $30,83 \%$

Ataluren analog $\quad 32,53 \%$ d

a $5.0 \mathrm{mmol}$ scale. ${ }^{\mathrm{b}} \mathrm{Temperature:} 25^{\circ} \mathrm{C}$. cNMR yield. Reaction conditions: 1.2 equiv hexamethyldisilane, $1.5 \mathrm{~mol} \% \mathrm{Pd}_{2} \mathrm{dba}_{3}, 9 \mathrm{~mol} \%$ JohnPhos, 5.0 equiv KF, 2.0 equiv $\mathrm{H}_{2} \mathrm{O}$, DMPU $(0.90 \mathrm{~mL}), 100{ }^{\circ} \mathrm{C}, 12 \mathrm{~h} .{ }^{\mathrm{d}} 6 \mathrm{~mol} \% \mathrm{MePhos} \mathrm{Pd} \mathrm{G} 4$ and 3.0 equiv $\mathrm{Na}^{+} \mathbf{1}^{-}$were used.

Next, we explored the reaction scope with respect to aryl bromides (Table 2). Silylation of $\mathbf{5}$ could be run even on a $5.0 \mathrm{mmol}$ scale to afford 6 in excellent yield (92\%). The reaction could tolerate various electronic and steric properties of substituents (6-11). Esters in $\mathbf{6}$ and $\mathbf{7}$ survived the silylation conditions. This outcome is intriguing given that trimethylsilanolates are generally used for the hydrolysis of esters. ${ }^{14}$ The substrate with formyl or acetyl group could be transformed in good yield to $\mathbf{8}$ or $\mathbf{9}$. In the case of $\mathbf{9}$, the reaction was performed at $25^{\circ} \mathrm{C}$ to suppress the formation of an a-arylated byproduct. Cyano and nitro groups could poison a palladium catalyst. While substrates with cyano group were converted into arylsilane 10 in good yield, arylsilane 11 with nitro group was obtained only in moderate yield. Fluoro and vinyl substituents were also confirmed to be compatible $(\mathbf{1 2}, \mathbf{1 3})$. Substrates with electron-rich substituents, such as methoxy ( $p-, m-, 0-\mathrm{OMe})$, silyloxy, amino, and amido-substituted aryls were generally transformed to arylsilanes (14-19). A wide range of heteroaryl trimethylsilanes could also be synthesized under our silylation reaction. Electron-rich heteroarenes such as benzofuran $\mathbf{2 0}$, benzothiophene $\mathbf{2 1}, N$-( $p$-toluenesulfonyl)indole $\mathbf{2 2}$, and $\mathrm{N}$-methylpyrrolopyridine $\mathbf{2 3}$ were obtained in excellent yields. A sterically hindered pyrazole was converted to the silylated product 24 albeit in moderate yield (53\%). Electron-deficient heteroarenes were also compatible. The conditions were amenable to the syntheses of quinoline $\mathbf{2 5}$, as well as pyridine $\mathbf{2 6}$ and pyrimidines $\mathbf{2 7}, \mathbf{2 8}$. The reaction was also applicable to the synthesis of known biologically relevant compounds (Table $2 \mathrm{C}$ ). Acetylcholinesterase inhibitor Zifrosilone ${ }^{15}$ (29) was synthesized from the commercially available 3'-bromo-2,2,2- 
trifluoromethylacetophenone in good yield. A potent inhibitor of the drug-resistant S31N mutant of the M2 ion channel of influenza A virus $\mathbf{3 0}^{16}$ was synthesized from the corresponding aryl bromide even in the presence of a free hydroxy and a secondary amino group.

In an effort to demonstrate the applicability of our method to the late-stage silylation, we tested several drugs and drug-like molecules containing aryl bromides (Table 2D). Trimethylsilylated analogs of Sulfadimethoxine $\mathbf{3 1}$ and Ataluren 32 were synthesized in $77 \%$ and 53\% respective yields from the corresponding aryl bromides. The bromide moiety of SC-558 was similarly converted to TMS group to give an Celecoxib analog 33 in $76 \%$ yield. Nicergoline was also trimethylsilylated to give an Ergot alkaloid analog 34 in 64\% yield. An increased amount of the catalyst and silylsilanolate was required for Ataluren and Celecoxib analogs whose oxadiazole and sulfonamide moiety might work inhibitively to the catalyst. Thus, in the case of Ataluren analog, the slower rate of the coupling reaction seemed to result in partial hydrolysis of the ester moiety in 32. Sila-analog of Fenazaquin $35,{ }^{17}$ in which tert-butyl group is replaced with trimethylsilyl group, was analogously synthesized from the corresponding aryl bromide in excellent yield. Just to compare the functional group tolerance, the known palladium-catalyzed silylation conditions ${ }^{6 \mathrm{~h}}$ using hexamethyldisilane was applied for the syntheses of relatively functionalized $\mathbf{2 8}$ and $\mathbf{3 1}$, which resulted in $31 \%$ and $34 \%$ respective yields. The reaction proceeded in concomitant with the formation of the reduced products both in ca. $30 \%$ yields with an about $30 \%$ recovery of the starting material (See SI). These results indicate that the new silylation strategy using sodium silylsilanolate is suitable for the highly versatile syntheses of sila-analogs of bioactive molecules.

We applied the optimized silylation conditions to other aryl halides and pseudohalides (Table 3). For electrondeficient arenes, iodide, triflate, and chloride were silylated to provide 6 in high yields. lodide could be transformed even at $25^{\circ} \mathrm{C}$. For an electron-rich series, aryl iodide was also converted to the corresponding product 14 in high yield while triflate and chloride showed low or no conversion even under the optimized conditions. Silylation of aryl triflate and chloride on more functionalized molecules was also achieved. The silylated products 36, 37 were obtained from estrone derivative $(X=\mathrm{OTf})$ or fenofibrate $(X=\mathrm{Cl})$ respectively in high yields. In the case of a protected $\mathrm{L}$-tyrosine derivative $(\mathrm{X}=\mathrm{OTf})$, the silylated product $\mathbf{3 8}$ was obtained in good yield albeit in an almost racemized form.

Table 3. Scope of Silylation of Aryl Halides and Pseudohalides.
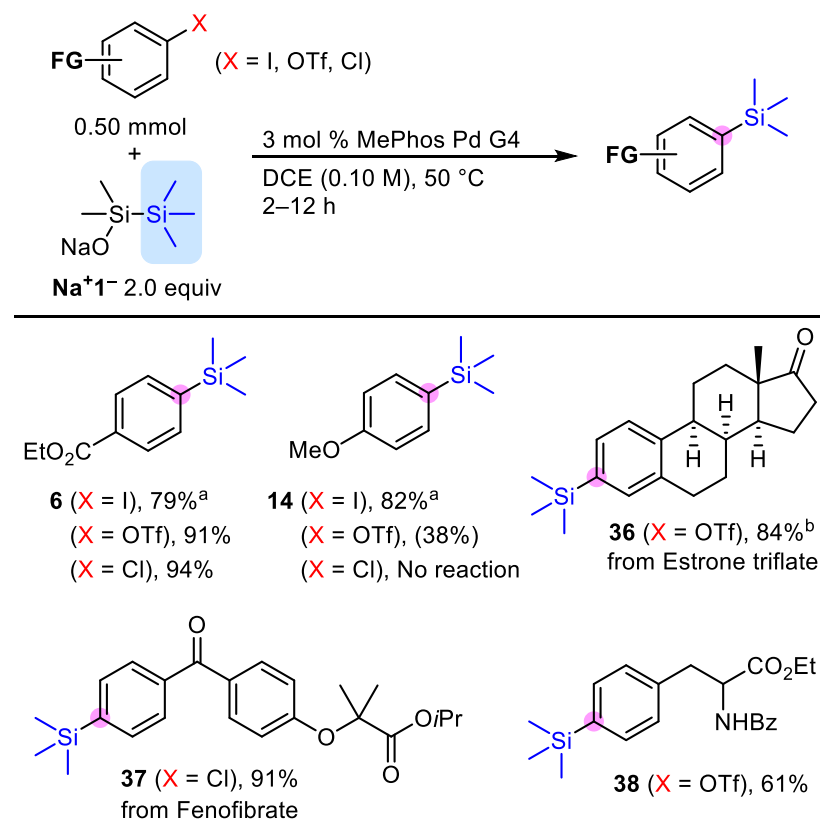

aTemperature: $25^{\circ} \mathrm{C} .{ }^{\mathrm{b}} 6 \mathrm{~mol} \% \mathrm{MePhos}$ Pd G4 was used.
Table 4. Scope of Silyl Groups.

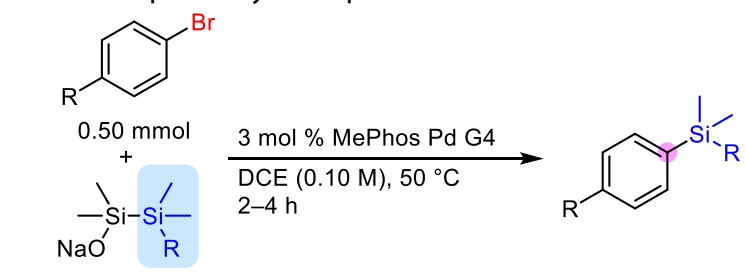

$\mathrm{Na}^{+} 2^{-}-\mathrm{Na}^{+} 4^{-} 2.0$ equiv

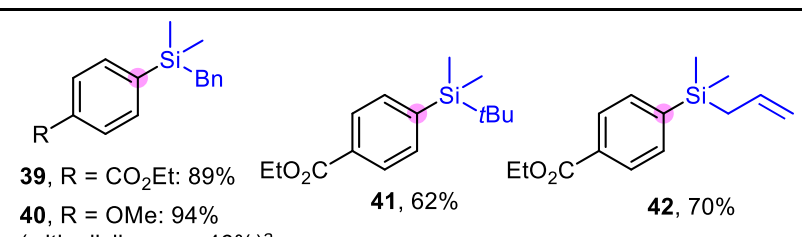

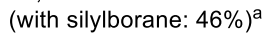

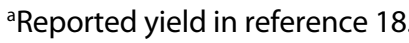

With $\mathrm{Na}^{+} \mathbf{2}^{-}-\mathrm{Na}^{+} \mathbf{4}^{-}$, introduction of other silyl groups was also possible in the current strategy (Table 4). Under the optimized conditions with $\mathrm{Na}^{+} \mathbf{2}^{-}$, benzyldimethylsilyl group could be introduced to both electron-deficient and donating arenes $\mathbf{3 9}$ and $\mathbf{4 0}$ in high yields. In the case of $p$-bromoanisole, the current conditions gave $p$ benzyldimethylsilylanisole $\mathbf{4 0}$ in $\mathbf{9 0 \%}$ yield, which is higher than the known result with silylborane-based conditions. ${ }^{18}$ A sterically hindered tert-butyldimethylsilyl (TBDMS) group was introduced with $\mathbf{~ N a}^{+} 3^{-}$to give 41 in $62 \%$ yield. While no coupling reaction with allyldimethylsilyl group has so far been reported with conventional silylating reagents, our silylation method with silylsilanolate $\mathbf{N a}^{+} \mathbf{4}^{-}$enabled an easy access to the allylsilylated arene $\mathbf{4 2}$. These results indicate that the core structure of silylsilanolate would be generally viable for the transmetalation of various silyl groups.

To gain mechanistic insights into the silylation with silylsilanolates, we conducted ${ }^{31} \mathrm{P}$ and ${ }^{19} \mathrm{~F}$ NMR experiments (Figure 3 and S1). T-shape complex SPhosPdBr $\left(4-\mathrm{FC}_{6} \mathrm{H}_{4}\right)(\mathbf{4 3})$ was synthesized from $4-\mathrm{FC}_{6} \mathrm{H}_{4} \mathrm{Br}$, $\mathrm{Pd}(\mathrm{Cod})\left(\mathrm{CH}_{2} \mathrm{SiMe}\right)_{2}$, and 
SPhos..$^{19}$ As reported by Hii, Pd complexes with SPhos such as $\mathbf{4 3}$ were known to show two signals corresponding to the monomer of $\mathbf{4 3}$ and its $\mu_{2}$-halo-bridged dimer (Figure $3 \mathrm{~A}$ ). ${ }^{20}$ Cationic Pd (II) species $\mathbf{4 4}$ was prepared in situ by the reaction of 43 with $\mathrm{NaBAr}_{4}$ at $0{ }^{\circ} \mathrm{C}\left(\mathrm{Ar}^{\mathrm{F}}=3,5-\left(\mathrm{CF}_{3}\right)_{2} \mathrm{C}_{6} \mathrm{H}_{3}\right){ }^{21}$ which showed a downfield shift of ${ }^{31} \mathrm{P}$ NMR signal ${ }^{22}$ at 49.4 ppm (Figure 3B). Upon treatment of $\mathbf{4 4}$ with 0.5 equiv of $\mathbf{~ N a}^{+} \mathbf{1}^{-}$at $-30^{\circ} \mathrm{C}$, a new ${ }^{31} \mathrm{P} \mathrm{NMR}$ signal appeared (37.8 ppm), in addition to the broadened signal for the remaining $\mathbf{4 4}$ (Figure 3C). After the addition of an additional 0.5 equiv of $\mathrm{Na}^{+} \mathbf{1}^{-}$to the solution at $-30^{\circ} \mathrm{C}, \mathbf{4 4}$ was fully consumed, leaving the species that shows the sharp signal at $38.0 \mathrm{ppm}$ with a broadened signal at $41.2 \mathrm{ppm}$ (Figure 3D). The stoichiometry obtained in these experiments revealed that the attack of $\mathbf{N a}^{+} \mathbf{1}^{-}$to $\mathbf{4 4}$ rapidly occurred and resulted in the formation of a Pd species $\mathbf{4 5}$ bearing a silylsilanolate substituent. ${ }^{119}$ We attributed the slight shift of the broadened signal of $\mathbf{4 4}$ in Figure $3 \mathrm{C}$ to the fast equilibrium between the free cationic $\mathbf{4 4}$ and a complex of $\mathbf{4 4}$ and $\mathbf{4 5}$. By analogy to Figure 3A, the sharp signal at $38.0 \mathrm{ppm}$ and the broad peak at $41.2 \mathrm{ppm}$ in Figure 3D could be respectively assigned as the monomeric species of $\mathbf{4 5}$ and its silanolatebridged dimer. ${ }^{19} \mathrm{~F}$ NMR study was separately conducted for the same time courses (See SI). The product that formed in the reaction was confirmed to be the coupled product 4-fluorotrimethylsilylbenzene from the ${ }^{19} \mathrm{~F}$ NMR spectrum. Also, after the solution of $\mathbf{4 5}$ was warmed to room temperature, the ${ }^{19} \mathrm{~F}$ NMR signal showed the disappearance of $\mathbf{4 5}$. These NMR experiments corroborated the hypothesis that silylsilanolate-coordinated species $\mathbf{4 5}$ was a viable intermediate for the palladium-catalyzed silylation.

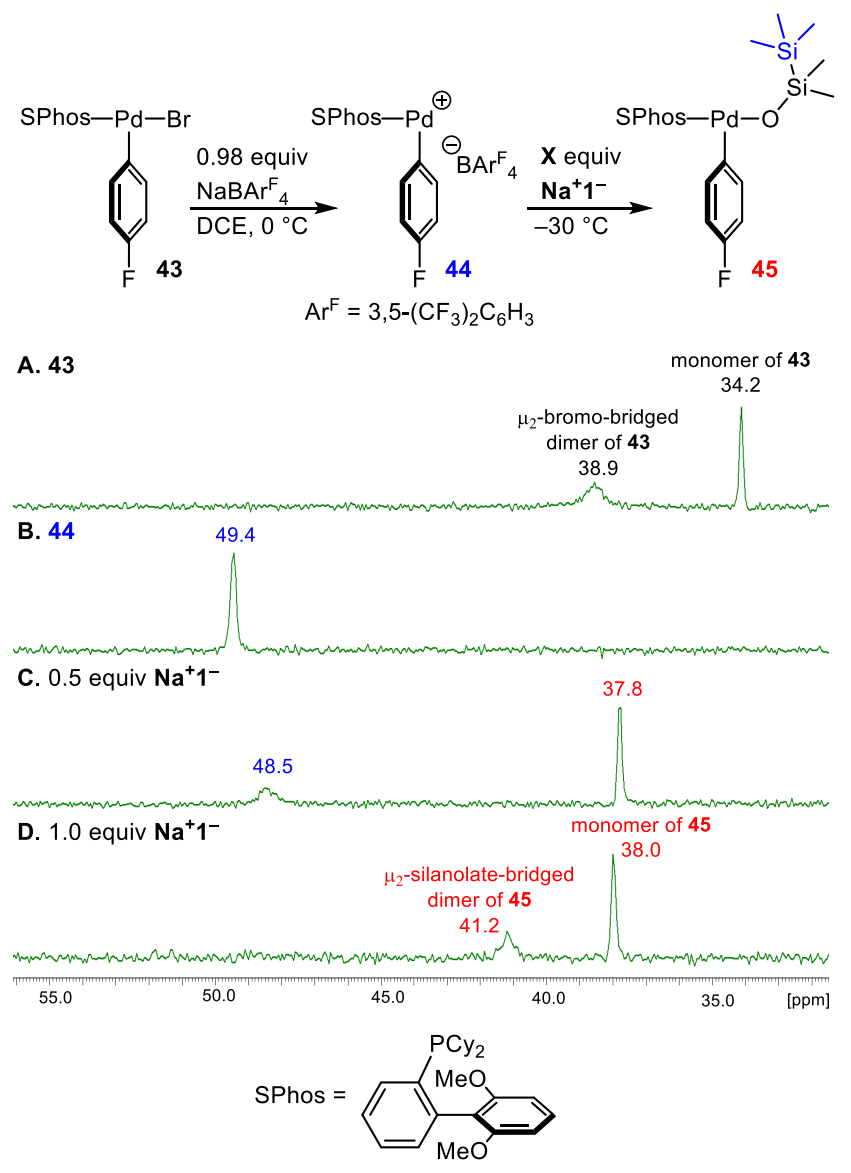

Figure 3. Sequential ${ }^{31} \mathrm{P}$ NMR Spectra on the Ligand Exchange of $\mathbf{4 3}$ with Sodium Silylsilanolate.

To figure out the mechanism of the migration of the silyl groups to palladium atom of $\mathbf{4 5}$, DFT calculations were carried out (Figure 4). Based on the results of the ${ }^{31} \mathrm{P}$ NMR experiments, silylsilanolate-coordinated arylpalladium INT1 was chosen as a reliable starting point of the calculated pathway. To simplify the calculations, the ligand was modeled as 2-(diisopropylphosphino)biphenyl. A pathway for the migration of the silyl group directly from INT-1 (nonassisted pathway) was initially examined. The energy profile is summarized on the left side of Figure 4 . The pathway for the direct elimination of dimethylsilanone (46) from INT-1 to afford INT-A2 via TS-A and INT-A1 was found to be endergonic probably because of the thermodynamically unfavorable generation of a silanone. As the calculated activation energy from INT-1 to TS-A is $34.8 \mathrm{kcal} / \mathrm{mol}$, direct transfer of the silyl group to give $\mathbf{4 7}$ is not a likely pathway. We next hypothesized that sodium silylsilanolates that exist in large excess compared with the palladium species would promote the migration of a silyl group. Experimental observations revealed that non-polar solvents such as DCE and toluene were effective for the silylation, so we assumed that an aggregated cluster of sodium silylsilanolates may have an effect on the migration process. To simplify the calculation, an activator was modeled as sodium 
trimethylsilanolate dimer $\mathbf{4 8}$. The energy profile with the aid of $\mathbf{4 8}$ is summarized on the right side of Figure 4 (silanolate dimer-assisted pathway). The complexation of INT-1 with the sodium trimethylsilanolate dimer $\mathbf{4 8}$ proceeds exergonically to afford INT-B1. The intramolecular transfer of the trimethylsilyl group to the palladium atom requires a lower activation barrier $\left(\Delta G^{\ddagger}=28.1 \mathrm{kcal} / \mathrm{mol}\right)$ via TS-B to afford INT-B2 than that via TS-A. In the calculated structure of TS-B shown in Figure 4, the silicate moiety on Si2 atom forms a trigonal bipyramidal structure where Si1 and $\mathrm{O} 1$ atoms occupy the apical positions. NBO analysis revealed that the NPA charge of the trimethylsilyl unit of the silylsilanolate in TS-B (-0.552 e) was significantly more negative than the one in TS-A1 (-0.110 e) (See SI). In addition, each of NPA charges of Si1 and Si2 atoms in TS-B is +0.875 e and +2.081 e, which indicates Si1 atom is more negatively charged. Thus, through the formation of silicate-like structure in TS-B, the trimethylsilyl unit containing Si1 atom is rendered anionic to result in the smooth combination of the Si1 unit with the nearby palladium atom. Dissociation of a silanolate bearing disiloxane moiety 49 from INT-B2 affords INT-B3. Cluster $\mathbf{4 9}$ that goes off in the course of the reaction would again assist in the activation of the transfer of the silyl group. Of note, our simplified calculation model based on a sodium silanolate dimer does not exclude the possibility of the interference of a larger cluster of silanolates. From these results, we conclude that the transfer of the silyl group proceeds with the aid of a cluster of silanolates that would exist in the reaction mixture. ${ }^{23} \mathrm{~A}$ calculation on the reductive elimination of $\mathbf{4 7}$ indicates that the final reductive elimination is a low-barrier process through TS-RE $\left(\Delta G^{\ddagger}=5.7 \mathrm{kcal} / \mathrm{mol}\right)$ to exergonically afford INT-B4. This result is consistent with the fact that such silylpalladium species was not observed either in the ${ }^{31} \mathrm{P}$ or ${ }^{19} \mathrm{~F}$ NMR experiments.

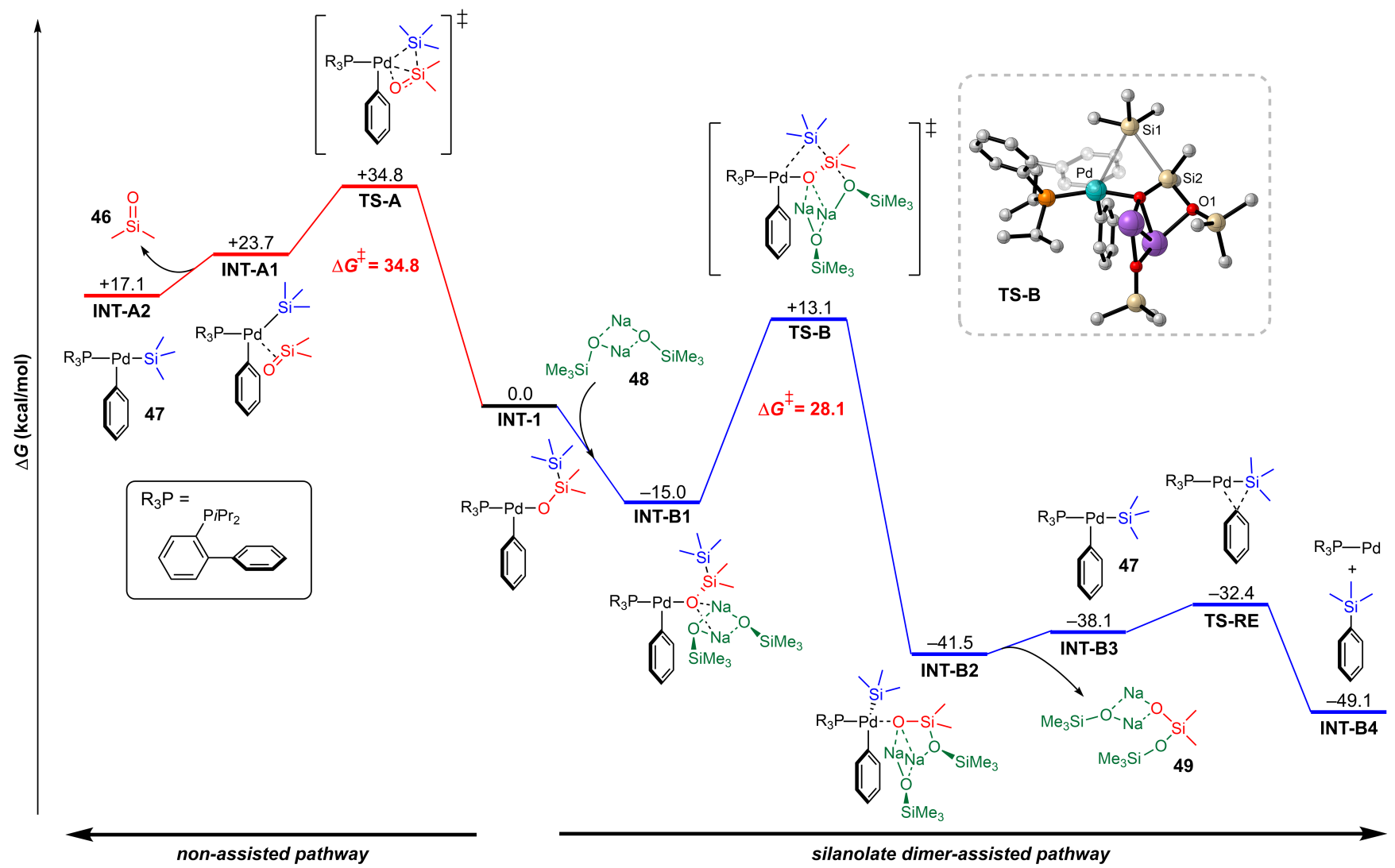

Figure 4. Energy Profile for Migration of Silyl Group of Silylsilanolate to Palladium Atom at the $\omega B$ 97X-D/def2-TZVP/SMD (DCE)// $\omega B$ 97X-D/def2-SVP Level of Theory at $323.15 \mathrm{~K}$.

In conclusion, we have developed a new class of practical silylating reagent, sodium silylsilanolates, and confirmed their efficiency for the delivery of silyl groups in the palladium-catalyzed silylation of aryl (pseudo)halides. The new silylation method with silylsilanolates allowed an introduction of a series of silyl groups including the ones that have been regarded to be laborious. A good functional group tolerance exhibited under the conditions proved an applicability to the late-stage silylation of drugs and complex molecules. Mechanistic studies with ${ }^{31} \mathrm{P}$ and ${ }^{19} \mathrm{~F}$ NMR experiments and DFT calculations revealed a plausible reaction mechanism for the intramolecular transfer of the terminal silyl group on a silanolate to palladium center, which was assisted by a cluster of silanolates. These results unveiled a broader potential versatility of sodium silylsilanolates as silylating reagents for a range of challenging silylating transformations. Development of other silylsilanolate species and further applications of alkali metal silylsilanolates in combination with other transition metal catalysts will be reported in due course. 


\title{
Supporting Information
}

The Supporting Information is available free of charge on the ACS Publications website.

Experimental details and characterization data (PDF)

\section{AUTHOR INFORMATION}

\section{Corresponding Authors}

Jun Shimokawa-Department of Chemistry, Graduate School of Science, Kyoto University, Kyoto 606-8502, Japan; orcid.org/0000-0002-4023-4640; Email: shimokawa@kuchem.kyoto-u.ac.jp

Hideki Yorimitsu—Department of Chemistry, Graduate School of Science, Kyoto University, Kyoto 606-8502, Japan; orcid.org/0000-0002-0153-1888; Email: yori@kuchem.kyoto-u.ac.jp

\author{
Authors \\ Hiroki Yamagishi-Department of Chemistry, Graduate School of Science, Kyoto University, Kyoto 606-8502, Japan. \\ Hayate Saito-Department of Chemistry, Graduate School of Science, Kyoto University, Kyoto 606-8502, Japan; \\ orcid.org/0000-0002-4549-7917
}

\section{Notes}

The authors declare no competing financial interest.

\section{ACKNOWLEDGMENT}

This work was supported by JSPS KAKENHI Grant Numbers JP21H01934, JP20J23393, JP19H00895, JP18J22838 and partly by JST CREST Grant Number JPMJCR19R4, Japan. H. Yamagishi acknowledges a JSPS Predoctoral Fellowship. J.S. thanks the support by The Sumitomo Foundation.

\section{REFERENCES}

(1) For reviews about silicon-containing drugs, see: (a) Tacke, R.; Dörrich, S. Drug Design Based on the Carbon/Silicon Switch Strategy. In Atypical Elements in Drug Design; Schwarz, J., Ed.; Topics in Medicinal Chemistry 17, 2016; pp 29-59. (b) Showell, G. A.; Mills, J. S. Chemistry Challenges in Lead Optimization: Silicon Isosteres in Drug Discovery. Drug Discov. 2003, 8, 551-556. (c) Sieburth, S. McN.; Chen, C.-A. Silanediol Protease Inhibitors: From Conception to Validation. Eur. J. Org. Chem. 2006, 311-322. (d) Meanwell, N. A. Synopsis of Some Recent Tactical Application of Bioisosteres in Drug Design. J. Med. Chem. 2011, 54, 2529-2591. (e) Franz, A. K.; Wilson, S. O. Organosilicon Molecules with Medicinal Applications. J. Med. Chem. 2013, 56, 388-405. (f) Fujii, S.; Hashimoto, Y. Progress in the Medicinal Chemistry of Silicon: C/Si Exchange and Beyond. Future Med. Chem. 2017, 9, 485-505. (g) Ramesh, R.; Reddy, D. S. Quest for Novel Chemical Entities through Incorporation of Silicon in Drug Scaffolds. J. Med. Chem. 2018, 61, 3779-3798.

(2) (a) Daiss, J. O.; Burschka, C.; Mills, J. S.; Montana, J. G.; Showell, G. A.; Fleming, I.; Gaudon, C.; Ivanova, D.; Gronemeyer, H.; Tacke, R. Synthesis, Crystal Structure Analysis, and Pharmacological Characterization of Disila-bexarotene, a Disila-Analogue of the RXR-Selective Retinoid Agonist Bexarotene. Organometallics 2005, 24, 3192-3199. (b) Bauer, J. B.; Lippert, W. P.; Dörrich, S.; Tebbe, D.; Burschka, C.; Christie, V. B.; Tams, D. M.; Henderson, A. P.; Murray, B. A.; Marder, T. B.; S. A. Przyborski; Tacke, R. Novel Silicon-Containing Analogues of the Retinoid Agonist Bexarotene: Syntheses and Biological Effect on Human Pluripotent Stem Cells. ChemMedChem 2011, 6, 1509-1517.

(3) Zhou, C.; Cheng, J.; Beadle, R.; Earley, F. G.; Li, Z.; Maienfisch, P. Design, Synthesis and Acaricidal Activities of Cyflumetofen Analogues Based on Carbon-Silicon isosteric Replacement. Bioorg. Med. Chem. 2020, 28, 115509.

(4) Barnes, M. J.; Conroy, R.; Miller, D. J.; Mills, J. S.; Montana, J. G.; Pooni, P. K.; Showell, G. A.; Walsh, L. M.; Warneck, J. B. H. Trimethylsilylpyrazoles as Novel Inhibitors of p38 MAP Kinase: A New Use of Silicon Bioisosteres in Medicinal Chemistry. Bioorg. Med. Chem. Lett. 2007, 17, 354-357.

(5) (a) Murata, M.; Suzuki, K.; Watanabe, S.; Masuda, Y. Synthesis of Arylsilanes via Palladium(0)-Catalyzed Silylation of Aryl Halides with Hydrosilane. J. Org. Chem. 1997, 62, 8569-8571. (b) Manoso, A. S.; DeShong, P. J. Org. Chem. 2001, 66, 7449-7455. (c) Yamanoi, Y. PalladiumCatalyzed Silylations of Hydrosilanes with Aryl Halides Using Bulky Alkyl Phosphine. J. Org. Chem. 2005, 70, 9607-9609. For a review, see: (d) Xu, Z.; Huang, W.-S.; Zhang, J.; Xu, L.-W. Recent Advances in Transition-Metal-Catalyzed Silylations of Arenes with Hydrosilanes: C-X Bond Cleavage or C-H Bond Activation Synchronized with Si-H Bond Activation. Synthesis 2015, 47, 3645-3668.

(6) (a) Matsumoto, H.; Nagashima, S.; Yoshihiro, K.; Nagai, Y. Silicon-Carbon Bond Formation by the Reaction of Disilanes with Halobenzenes in the Presence of Tetrakis(triphenylphosphine)palladium(0). J. Organomet. Chem. 1975, 85, C1-C3. (b) Azarian, D.; Dua, S. S.; Eaborn, C.; Walton, D. R. M. Reactions of Organic Halides with $\mathrm{R}_{3} \mathrm{MMR}_{3}$ Compounds $(\mathrm{M}=\mathrm{Si}, \mathrm{Ge}, \mathrm{Sn}$ ) in the Presence of Tetrakis(triarylphosphine)palladium. J. Organomet. Chem. 1976, 117, C55-C57. (c) Eaborn, C.; Griffiths, R. W.; Pidcock, A. Further Studies on Reactions of Organic Halides with Disilanes Catalysed by Transition Metal Complexes. J. Organomet. Chem. 1982, 225, 331-341. (d) Hatanaka, Y.; Hiyama, T. Palladiummediated Silylation of Organic Halides with Disilane/F- reagent. Tetrahedron Lett. 1987, 28, 4715-4718. (e) Babin, P.; Bennetau, B.; Theurig, M.; Dunoguès, J. Synthèse d'Aryl- et Hétéroarylsilanes par Scission de l'Hexaméthyldisilane. J. Organomet. Chem. 1993, 446, 135-138. (f) Ishii, Y.; Chatani, N.; Yorimitsu, S.; Murai, S. Rhodium-Catalyzed Si-F Exchange Reaction between Fluorobenzenes and a Disilane. Catalytic Reaction Involving Cleavage of C-F Bonds. Chem. Lett. 1998, 27, 157-158. (g) Shirakawa, E.; Kurahashi, T.; Yoshida, H.; Hiyama, T. Diphenylphosphinophenolate: a Ligand for the Palladium-Catalysed Silylation of Aryl Halides Activating Simultaneously both Palladium and Silicon. Chem. Commun. 2000, 1895-1896. (h) Gooßen, L. J.; Ferwanah, A.-R. S. A Mild and Efficient Protocol for the Catalytic Silylation of Aryl Bromides. Synlett 2000, 1801-1803. (i) Denmark, S. E.; Kallemeyn, J. M. Palladium-Catalyzed Silylation of Aryl Bromides Leading to Functionalized Aryldimethylsilanols. Org. Lett. 2003, 5, 3483-3486. (j) Iwasawa, T.; Komano, T.; Tajima, A.; Tokunaga, M.; Obora, Y.; Fujihara, T.; Tsuji, Y. Phosphines Having a 2,3,4,5-Tetraphenylphenyl Moiety: Effective Ligands in Palladium-Catalyzed Transformations of Aryl Chlorides. Organometallics 2006, 25, 4665-4669. (k) Tobisu, M.; Kita, Y.; Chatani, N. Rh(I)-Catalyzed Silylation of Aryl and Alkenyl Cyanides Involving the Cleavage of C-C and Si-Si Bonds. J. Am. Chem. Soc. 2006, 128, 8152-8153. (I) McNeill, E.; Barder, T. E.; Buchwald, S. L. Palladium-Catalyzed Silylation of Aryl Chlorides with Hexamethyldisilane. Org. Lett. 2007, 9, 3785-3788. (m) Tobisu, M.; Kita, Y.; Ano, Y.; Chatani, N. RhodiumCatalyzed Silylation and Intramolecular Arylation of Nitriles via the Silicon-Assisted Cleavage of Carbon-Cyano Bonds. J. Am. Chem. Soc. 2008, 130, 15982-15989. (n) Yamamoto, Y.; Matsubara, H.; Murakami, K.; Yorimitsu, H.; Osuka, A. Activator-Free Palladium-Catalyzed 
Silylation of Aryl Chlorides with Silylsilatranes. Chem. Asian J. 2015, 10, 219-224. (o) Fukui, K.; Saito, H.; Shimokawa, J.; Yorimitsu, H. Palladium-Catalyzed Silylation of Aryl Chlorides with Bulky Dialkoxydisilanes. Synlett 2020, 31, 1328-1332.

(7) For reviews on silylboranes, see: (a) Oestreich, M.; Hartmann, E.; Mewald, M. Activation of the Si-B Interelement Bond: Mechanism, Catalysis, and Synthesis. Chem. Rev. 2013, 113, 402-441. (b) Feng, J.-J.; Mao, W.; Zhang, L.; Oestreich, M. Activation of the Si-B Interelement Bond Related to Catalysis. Chem. Soc. Rev. 2021, 50, 2010-2073.

(8) (a) Zhang, J.; Zhang, Y.; Geng, S.; Chen, S.; Liu, Z.; Zeng, X.; He, Y.; Feng, Z. C-O Bond Silylation Catalyzed by Iron: A General Method for the Construction of Csp²-Si Bonds. Org. Lett. 2020, 22, 2669-2674. (b) Wu, Y.; Huang, Y.-H.; Chen, X.-Y.; Wang, P. Site-Selective Silylation of Arenes Mediated by Thianthrene S-Oxide. Org. Lett. 2020, 22, 6657-6661.

(9) Yamamoto, E.; Shishido, R.; Seki, T.; Ito, H. Tris(trimethylsilyl)silylboronate Esters: Novel Bulky, Air- and Moisture-Stable Silylboronate Ester Reagents for Boryl Substitution and Silaboration Reactions. Organometallics 2017, 36, 3019-3022.

(10) Kurahashi, T.; Hata, T.; Masai, H.; Kitagawa, H.; Shimizu, M.; Hiyama, T. Geminal Dimetalation of Alkylidene-type Carbenoids with Silylboranes and Diborons. Tetrahedron 2002, 58, 6381-6395.

(11) (a) Hirabayashi, K.; Kawashima, J.; Nishihara, Y.; Mori, A.; Hiyama, T. A New Transformation of Silanols. Palladium-Catalyzed CrossCoupling with Organic Halides in the Presence of Silver(I) Oxide. Org. Lett. 1999, 1, 299-301. (b) Denmark, S. E.; Sweis, R. F. Fluoride-Free Cross-Coupling of Organosilanols. J. Am. Chem. Soc. 2001, 123, 6349-6440. (c) Hirabayashi, K.; Mori, A.; Kawashima, J.; Suguro, M.; Nishihara, Y.; Hiyama, T. Palladium-Catalyzed Cross-Coupling of Silanols, Silanediols, and Silanetriols Promoted by Silver(I) Oxide. J. Org. Chem. 2000, 65, 5342-5349. (d) Denmark, S. E.; Sweis, R. F. Design and Implementation of New, Silicon-Based, Cross-Coupling Reactions: Importance of Silicon-Oxygen Bonds. Acc. Chem. Res. 2002, 35, 835-846. (e) Denmark, S. E.; Smith, R. C.; Chang, W.-T. T.; Muhuhi, J. M. Cross-Coupling Reactions of Aromatic and Heteroaromatic Silanolates with Aromatic and Heteroaromatic Halides. J. Am. Chem. Soc. 2009, 131, 3104-3118. (f) Denmark, S. E.; Smith, R. C. Mechanistic Duality in Palladium-Catalyzed Cross-Coupling Reactions of Aryldimethylsilanolates. Intermediacy of an 8-Si-4 Arylpalladium(II) Silanolate. J. Am. Chem. Soc. 2010, 132, 1243-1245. (g) Tymonko, S. A.; Smith, R. C.; Ambrosi, A.; Ober, M. H.; Wang, H.; Denmark, S. E. Mechanistic Significance of the Si-O-Pd Bond in the Palladium-Catalyzed Cross-Coupling Reactions of Arylsilanolates. J. Am. Chem. Soc. 2015, 137, 6200-6218.

(12) In the case of $\mathbf{4}$, the use of preformed allylic zinc reagent showed a better reproducibility than in the Sakurai's seminal work. Sanji, T.; Iwata, M.; Watanabe M.; Hoshi, T.; Sakurai, H. Highly Selective Mono- and Polyallylation of Polychlorosilanes and Polychlorodisilanes. Organometallics 1998, 17, 5068-5071.

(13) The new precatalyst, MePhos Pd G4, was synthesized according to the reported procedure: Bruno, N. C.; Niljianskul, N.; Buchwald, S. L. N-Substituted 2-Aminobiphenylpalladium Methanesulfonate Precatalysts and Their Use in C-C and C-N Cross-Couplings. J. Org. Chem. 2014, 79, 4161-4166. The detail of the synthesis is described in SI.

(14) (a) Laganis, E. D.; Chenard, B. L. Metal Silanolates: Organic Soluble Equivalents for $\mathrm{O}^{-2}$. Tetrahedron Lett. 1984, 25, 5831-5834. (b) Lovrić, M.; Cepanec, l.; Litvić, M.; Bartolinčić, A.; Vinković, V. Scope and Limitations of Sodium and Potassium Trimethylsilanolate as Reagents for Conversion of Esters to Carboxylic Acids. Croat. Chim. Acta 2007, 80, 109-115.

(15) (a) Hornsperger, J.-M.; Collard, J.-N.; Heydt, J.-G.; Giacobini, E.; Funes, S.; Dow, J.; Schirlin, D. Trimethylsilylated Trifluoromethyl Ketones, a Novel Class of Acetylcholinesterase Inhibitors: Biochemical and Pharmacological Profile of MDL 73,745. Biochem. Soc. Trans. 1994, 22, 758-763. (b) Cutler, N. R.; Seifert, R. D.; Schleman, M. M.; Sramek, J. J.; Szylleyko, O. J.; Howard, D. R.; Barchowsky, A.; Wardle, T. S.; Brass, E. P. Acetylcholinesterase Inhibition by Zifrosilone: Pharmacokinetics and Pharmacodynamics. Clin. Pharmacol. Ther. 1995, 58, 54-61. (c) Zhu, X. D.; Giacobini, E.; Hornsperger, J.-M. Effect of MDL 73,745 on Acetylcholine and Biogenic Amine Levels in Rat Cortex. Eur. J. Pharmacol. 1995, 276, 93-99.

(16) Hu, Y.; Wang, Y.; Li, F.; Ma, C.; Wang, J. Design and Expeditious Synthesis of Organosilanes as Potent Antivirals Targeting Multidrugresistant Influenza A Viruses. Eur. J. Med. Chem. 2017, 135, 70-76.

(17) Dreikorn, B. A.; Suhr, R. G.; Jourdan, G. P.; Wright, I. G. Quinazoline Derivatives. Eur. Pat. Appl. 0326329A2, 1989.

(18) Shishido, R.; Uesugi, M.; Takahashi, R.; Mita, T.; Ishiyama, T.; Kubota, K.; Ito, H. General Synthesis of Trialkyl- and Dialkylarylsilylboranes: Versatile Silicon Nucleophiles in Organic Synthesis. J. Am. Chem. Soc. 2020, 142, 14125-14133.

(19) Molloy, J. J.; Seath, C. P.; West, M. J.; McLaughlin, C.; Fazakerley, N. J.; Kennedy, A. R.; Nelson, D. J.; Watson, A. J. B. Interrogating Pd(II) Anion Metathesis Using a Bifunctional Chemical Probe: A Transmetalation Switch. J. Am. Chem. Soc. 2018, 140, 126-130.

(20) Brazier, J. B.; Newton, M. A.; Barreiro, E. M.; Adrio, L. A.; Naya, L.; Hii, K. K. Solvent-Dependent Nuclearity, Geometry and Catalytic Activity of [(SPhos)Pd(Ph)Cl]2. Dalton Trans. 2017, 46, 7223-7231.(21) Borrajo-Calleja, G. M.; Bizet, V.; Besnard, C.; Mazet, C. Mechanistic Investigation of the Pd-Catalyzed Intermolecular Carboetherification and Carboamination of 2,3-Dihydrofuran: Similarities, Differences, and Evidence for Unusual Reaction Intermediates. Organometallics 2017, 36, 3553-3563.

(22) (a) Shimomaki, K.; Murata, K.; Martin, R.; Iwasawa, N. Visible-Light-Driven Carboxylation of Aryl Halides by the Combined Use of Palladium and Photoredox Catalysts. J. Am. Chem. Soc. 2017, 139, 9467-9470. (b) McGarry, R.; McDaniel, M.; Chan, B. C.; O'Connor, A. R. Synthesis and characterization of ( $\pi$-allyl)palladium(II) complexes containing dialkylbiaryl phosphine ligands. Polyhedron 2016, 114, $101-109$.

(23) We also calculated the pathway of the migration of a silyl group with the aid of trimethylsilanolate monomer. This result indicates that in the silanolate monomer-assisted pathway, the activation barrier of cleavage of the Si-Si bond of silylsilanoalte is higher than the one in the non-assisted pathway. Details of the calculation result are shown in SI. 